\title{
ANALISA BAHAN ISOLASI PIPA SALURAN UAP PANAS PADA BOILER UNTUK MEMINIMALISASI HEAT LOSS
}

\author{
Muntolib**) dan Rusdiyantoro*)
}

\begin{abstract}
Abstrak
Uap panas merupakan sumber utama dalam mengolah produksi, aliran pipa uap panas selalu dipengaruhi udara bebas, karena itu harus dilakukan pemilihan bahan isolasi jenis mineral wool, calcium silicate dan ceramic fiber blanket dengan membuat model simulasi untuk menentukan bahan yang paling tepat dalam mengurangi kehilangan panas. Analisa dilakukan dengan menghitung jumlah kehilangan panas tanpa menggunakan bahan isolasi dan menggunakan isolasi dengan ketebalan bervariabel. Proses analisa dilakukan pada suhu $150^{\circ} \mathrm{C}$ dengan hasil isolasi mineral wool tebal $25 \mathrm{~mm}$ sebesar 5.714 watt, tebal $50 \mathrm{~mm}$ sebesar 3.489 watt dan tebal $75 \mathrm{~mm}$ sebesar 2.633 watt. Sedangkan hasil isolasi calsium silicate tebal $25 \mathrm{~mm}$ sebesar 7.774 watt, tebal $50 \mathrm{~mm}$ sebesar 4.913 watt dan tebal $75 \mathrm{~mm}$ sebesar 3.756 watt. Sedangkan hasil isolasi ceramic fiber blanket tebal $25 \mathrm{~mm}$ sebesar 6.756 watt, tebal $50 \mathrm{~mm}$ sebesar 4.197 watt dan tebal $75 \mathrm{~mm}$ sebesar 3.188 watt. Bahan isolasi mineral wool memiliki hasil terbaik dibandingkan calcium silicate dan ceramic fiber blanket. Kesimpulan pemilihan bahan isolasi dipengaruhi nilai termal konduktivitas dan tebal bahan.
\end{abstract}

Kata kunci : perpindahan panas, kehilangan panas, heat loss, isolasi, boiler

\section{PENDAHULUAN.}

Uap panas merupakan sumber utama dalam mengolah produksi, aliran uap panas yang melalui pipa selalu dipengaruhi udara bebas. Selama ini banyak industri yang melindungi pipa tersebut dengan isolasi namun mengabaikan perhitungan kehilangan panas yang terjadi dalam aliran pipa uap tersebut, akibatnya perusahaan tidak mengetahui berapa banyak uap yang terbuang ke udara selama mengalir pada saluran pipa uap dan tentunya pemanfaatan uap tersebut untuk produksi kurang maksimal.

Oleh karena itu perlu dilakukan pemilihan bahan isolasi diantaranya jenis mineral wool, calcium silicate dan ceramic fiber blanket yang sering banyak digunakan, dengan cara membuat model simulasi dalam keadaan steady untuk menentukan bahan yang paling tepat dalam mengurangi kehilangan panas. Diharapkan analisa simulasi ini dapat dipakai pihak industri agar mampu memilih jenis material isolasi dan mengetahui jumlah panas yang bisa diselamatkan selama ini, sehingga proses produksi meningkat dan mampu menjaga lingkungan kerja dari suhu panas.

Tujuan dari penelitian ini adalah membuat model simulasi untuk menganalisa dan menentukan jenis - jenis isolasi yang tepat untuk mengurangi panas yang hilang. Serta mengetahui cara penghitungan jumlah panas yang hilang selama menuju proses produksi. Adapun manfaat yang dapat diperoleh dari penelitian ini adalah memberi masukan terhadap pihak perusahaan agar mampu memilih jenis material isolasi, sehingga proses produksi meningkat., mampu menjaga lingkungan kerja dari suhu panas yang diakibatkan dari panasnya pipa uap serta mampu menekan seminimal mungkin terhadap operasional boiler sehingga dapat menambah masa pemakaian boiler.

\section{METODE PENELITIAN.}

\section{Metode Pengumpulan Data}

Metode pengumpulan data yang dilakukan adalah dengan metode observasi yang meliputi luas permukaan pipa, jenis dan ketebalan isolasi, suhu operasional, suhu permukaan isolasi dan suhu lingkungan. Serta juga menggnakan metode literature untuk mencari nilai thermal konduktivitas bahan isolasi, aluminium dan thermal konveksi rata-rata.

\section{Metode Analisa Data}

Tahap pertama dengan menganalisa kehilangan panas tanpa menggunakan bahan isolasi, dengan menggunakan rumus dikemukaan oleh Frank Kreith (1997; 12)

\footnotetext{
**) Mahasiswa Teknik Industri

*) Dosen Teknik Industri

Universitas PGRI Adi Buana Surabaya
} 
Konveksi menyatakan laju perpindahan panas dengan cara konveksi antara suatu permukaan dan suatu fluida dapat dihitung dengan hubungan :

$$
Q=\bar{h} A \Delta T
$$

Tahap kedua dengan menganalisa kerugian panas yang hilang menggunakan bahan isolasi berupa mineral wool, calsium silicate dan ceramic fiber blanket.

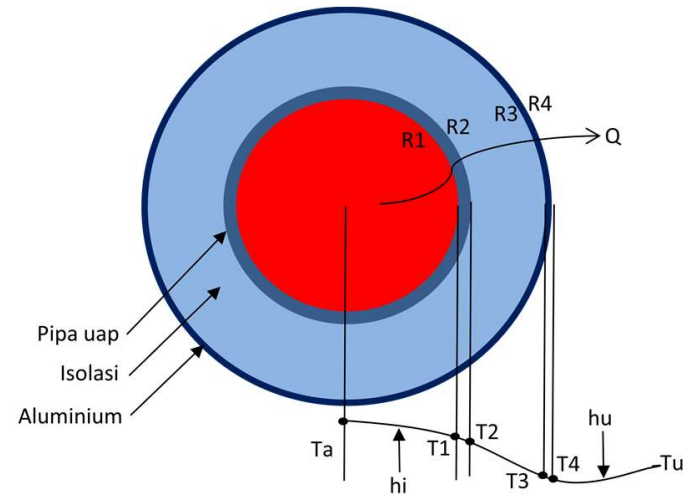

Gambar 1. Potongan saluran pipa yang di isolasi

Analisa hanya difokuskan pada bahan isolasi, sehingga analisa ini mengabaikan perpindahan panas pada dinding pipa saluran uap.

a) Perpindahan panas di dalam isolasi setiap satuan panjang :

$$
q=\frac{2 \pi k_{\text {iso }} l}{\operatorname{In}\left(r_{3} / r_{2}\right)}\left(T_{2}-T_{3}\right)=\frac{T_{2}-T_{3}}{R_{3}}
$$

b) Perpindahan panas di dalam aluminium sheet diperoleh,

$$
q=\frac{2 \pi k_{\text {alm }} l}{\operatorname{In}\left(r_{4} / r_{3}\right)}\left(T_{3}-T_{4}\right)=\frac{T_{3}-T_{4}}{R_{4}}
$$

c) Perindahan panas dari permukaan aluminium ke udara secara konveksi :

$$
q=2 \pi r_{4} l \bar{h}_{u}\left(T_{4}-T_{u}\right)=\frac{T_{4}-T_{u}}{R_{5}}
$$

Nilai $Q$ didapatkan dengan menjumlahkan ke - 3 persamaan suhu di atas, sehingga diperoleh :

$$
\begin{aligned}
\mathrm{Q} & =\frac{\left(\mathrm{T}_{\mathrm{a}}-\mathrm{T}_{\mathrm{u}}\right)}{\sum \mathrm{R}} \text { dengan } \mathrm{R} \text { total tahanan } \\
\sum \mathrm{R} & =\frac{\mathrm{In} \frac{\mathrm{R} 3}{\mathrm{R} 2}}{2 \pi \mathrm{k}_{\mathrm{iso}}}+\frac{\operatorname{In} \frac{\mathrm{R} 4}{\mathrm{R} 3}}{2 \pi \mathrm{k}_{\mathrm{alm}}}+\frac{1}{\text { hu. }(2 \pi \mathrm{R} 4)}
\end{aligned}
$$

\section{HASIL PENELITIAN.}

\section{Penyajian Data Parameter}

1. Penentuan luas permukaan pipa saluran, suhu operasional, suhu permukaan dan suhu lingkungan.

Dalam analisa ini penulis

\begin{tabular}{|c|c|c|c|c|c|c|c|c|c|}
\hline \multirow{2}{*}{ No } & \multirow{2}{*}{ Nama proyek } & \multicolumn{2}{|c|}{ Pipa } & \multicolumn{2}{|c|}{$\begin{array}{l}\text { Mineral } \\
\text { wool }\end{array}$} & \multicolumn{2}{|c|}{$\begin{array}{l}\text { Calcium } \\
\text { silicate }\end{array}$} & \multicolumn{2}{|c|}{$\begin{array}{c}\text { Ceramic } \\
\text { fiber blanket }\end{array}$} \\
\hline & & $\begin{array}{c}\varnothing \\
\text { (inch) }\end{array}$ & $\begin{array}{l}\mathrm{L} \\
(\mathrm{m})\end{array}$ & $\begin{array}{l}\mathrm{Ta} \\
\left({ }^{\circ} \mathrm{C}\right)\end{array}$ & $\begin{array}{l}\text { Ts } \\
\left({ }^{\circ} \mathrm{C}\right)\end{array}$ & $\begin{array}{l}\mathrm{Ta} \\
\left({ }^{\circ} \mathrm{C}\right)\end{array}$ & $\begin{array}{l}\text { Ts } \\
\left({ }^{\circ} \mathrm{C}\right)\end{array}$ & $\begin{array}{l}\mathrm{Ta} \\
\left({ }^{\circ} \mathrm{C}\right)\end{array}$ & $\begin{array}{l}\text { Ts } \\
\left({ }^{\circ} \mathrm{C}\right)\end{array}$ \\
\hline 1. & $\begin{array}{l}\text { Isolasi pipa panas di PT. Sura } \\
\text { Pratista Hutama, Sidoarjo }\end{array}$ & 2 & 45 & 105 & 38 & 105 & 39.5 & 105 & 40 \\
\hline 2. & $\begin{array}{l}\text { Isolasi pipa panas di CV. } \\
\text { Subur Jaya, Tulungagung }\end{array}$ & 4 & 95 & 155 & 44 & 155 & 42 & 155 & 43.5 \\
\hline 3. & $\begin{array}{l}\text { Isolasi pipa panas di CV. } \\
\text { Subur Jaya, Tulungagung }\end{array}$ & 6 & 74 & 155 & 44 & 155 & 42 & 155 & 43.5 \\
\hline 4. & $\begin{array}{l}\text { Isolasi pipa panas di CV. } \\
\text { Subur Jaya, Tulungagung }\end{array}$ & 10 & 11 & 155 & 44 & 155 & 42 & 155 & 43.5 \\
\hline
\end{tabular}
menggunakan data dari beberapa proyek yang sudah pernah dikerjakan di beberapa perusahaan sesuai tabel 1 .

Tabel 1. Data hasil penelitian dengan bahan isolasi mineral wool, calcium silicate dan ceramic fiber blanket 


\begin{tabular}{clcccccccc}
\hline 5. & $\begin{array}{l}\text { Isolasi pipa uap panas di PG. } \\
\text { Pangka, Tegal }\end{array}$ & 6 & 78 & 165 & 48 & 165 & 43 & 165 & 44 \\
\hline 6. & $\begin{array}{l}\text { Isolasi pipa uap panas di PG. } \\
\text { Pangka, Tegal }\end{array}$ & 8 & 105 & 165 & 48 & 165 & 43 & 165 & 44 \\
\hline 7. & $\begin{array}{l}\text { Isolasi pipa panas di PT.Bina } \\
\text { Karya Prima, Gresik }\end{array}$ & 4 & 50 & 176 & 52 & 176 & 44.6 & 176 & 43.5 \\
\hline 8. & $\begin{array}{l}\text { Isolasi pipa panas di } \\
\text { PT.Matahari Sakti, Surabaya }\end{array}$ & 8 & 8 & 110 & 39 & 110 & 40.4 & 110 & 41 \\
\hline 9. & $\begin{array}{l}\text { Isolasi pipa panas di PT.Perta } \\
\text { Daya Gas, Semarang }\end{array}$ & 6 & 22 & 174 & 52 & 174 & 44 & 174 & 46 \\
\hline 10. & $\begin{array}{l}\text { Isolasi pipa panas di PT.PJB } \\
\text { Paiton }\end{array}$ & 6 & 12 & 140 & 44 & 140 & 41.5 & 140 & 42 \\
\hline & Jumlah Rata - rata & $\mathbf{6}$ & $\mathbf{5 0}$ & $\mathbf{1 5 0}$ & $\mathbf{4 5 , 3}$ & $\mathbf{1 5 0}$ & $\mathbf{4 2 , 2}$ & $\mathbf{1 5 0}$ & $\mathbf{4 3 , 1}$ \\
\hline
\end{tabular}

Sesuai tabel 1 di hasilkan data :

a. Luas permukaan $(A)=\pi \times O D \times L=$ $3,14 \times 0,1683 \times 50=26,423 \mathrm{~m}^{2}$

b. Suhu operasional $(\mathrm{Ta})$ yaitu $150^{\circ} \mathrm{C}$

c. Suhu permukaan (Ts), Pada bahan isolasi mineral wool $45,3{ }^{\circ} \mathrm{C}$, bahan isolasi calcium silicate $42,2{ }^{\circ} \mathrm{C}$ dan bahan isolasi ceramic fiber blanket $43,1^{\circ} \mathrm{C}$

d. Suhu lingkungan (Tu) yaitu $35^{\circ} \mathrm{C}$.

2. Ketebalan bahan isolasi yang di analisa adalah tebal $25 \mathrm{~mm}$, tebal $50 \mathrm{~mm}$ dan tebal $75 \mathrm{~mm}$

3. Termal konduktivitas bahan isolasi yang di analisa sesuai tabel 2

Tabel 2. Nilai termal konduktivitas bahan isolasi pada suhu operasional $150{ }^{\circ} \mathrm{C}$

\begin{tabular}{clc}
\hline No & \multicolumn{1}{c}{ Jenis bahan } & $\begin{array}{c}\text { Termal konduktivitas }(\mathrm{W} / \mathrm{m} . \mathrm{k}) \\
\text { Pada Suhu } 150^{\circ} \mathrm{C}\end{array}$ \\
\hline 1. & Mineral wool & 0,049 \\
\hline 2. & Calcium silicate & 0,07154 \\
\hline 3. & Ceramic fiber blanket & 0,06 (pada suhu $\left.260^{\circ} \mathrm{C}\right)$ \\
\hline
\end{tabular}

Sedangkan nilai termal konduktivitas aluminium adalah $237 \mathrm{~W} / \mathrm{m} . \mathrm{k}$.

4. Nilai - nilai properti gas pada tekanan atmosfer

Nilai - nilai properti gas pada tekanan atmosfer (tabel 3) digunakan untuk menentukan bilangan Nusselt, Grashof, Reyleigh dan Prandtl, untuk mendapatkan nilai konduktivitas termal konveksi rata-rata dari permukaan ke udara lingkungan $(\mathrm{h})$, 
Tabel 3. Nilai - nilai properti gas pada tekanan atmosfer

\begin{tabular}{|c|l|l|l|l|l|l|l|}
\hline $\begin{array}{c}T \\
(\mathrm{~K})\end{array}$ & $\begin{array}{c}\rho \\
\left(\mathrm{kg} / \mathrm{m}^{3}\right)\end{array}$ & $\begin{array}{c}c_{p} \\
(\mathrm{~J} / \mathrm{kg} \cdot \mathrm{K})\end{array}$ & $\begin{array}{c}\mu \\
(\mathrm{kg} / \mathrm{m} \cdot \mathrm{s})\end{array}$ & $\begin{array}{c}v \\
\left(\mathrm{~m}^{2} / \mathrm{s}\right)\end{array}$ & $\begin{array}{c}k \\
(\mathrm{~W} / \mathrm{m} \cdot \mathrm{K})\end{array}$ & $\begin{array}{c}\alpha \\
\left(\mathrm{m}^{2} / \mathrm{s}\right)\end{array}$ & Pr \\
\hline \multicolumn{7}{|c|}{ Udara } \\
\hline 100 & 3,6010 & $1,0266 \times 10^{3}$ & $0,6924 \times 10^{-5}$ & $1,923 \times 10^{-6}$ & 0,009246 & $0,0250 \times 10^{-4}$ & 0,768 \\
150 & 2,3675 & 1,0099 & 1,0283 & 4,343 & 0,013735 & 0,0574 & 0,756 \\
200 & 1,7684 & 1,0061 & 1,3289 & 7,490 & 0,01809 & 0,1016 & 0,739 \\
250 & 1,4128 & 1,0053 & 1,5990 & 11,310 & 0,02227 & 0,1568 & 0,722 \\
300 & 1,1774 & 1,0057 & 1,8462 & 15,690 & 0,02624 & 0,2216 & 0,708 \\
350 & 0,9980 & 1,0090 & 2,075 & 20,76 & 0,03003 & 0,2983 & 0,697 \\
400 & 0,8826 & 1,0140 & 2,286 & 25,90 & 0,03365 & 0,3760 & 0,689 \\
450 & 0,7833 & 1,0207 & 2,484 & 31,71 & 0,03707 & 0,4636 & 0,683 \\
500 & 0,7048 & 1,0295 & 2,671 & 37,90 & 0,04038 & 0,5564 & 0,680 \\
550 & 0,6423 & 1,0392 & 2,848 & 44,27 & 0,04360 & 0,6532 & 0,680 \\
600 & 0,5879 & 1,0551 & 3,018 & 51,34 & 0,04659 & 0,7512 & 0,682 \\
650 & 0,5430 & 1,0635 & 3,177 & 58,51 & 0,04953 & 0,8578 & 0,682 \\
700 & 0,5030 & 1,0752 & 3,332 & 66,25 & 0,05230 & 1,9672 & 0,684 \\
750 & 0,4709 & 1,0856 & 3,481 & 73,91 & 0,05509 & 1,0774 & 0,686 \\
800 & 0,4405 & 1,0978 & 3,625 & 82,29 & 0,05779 & 1,1951 & 0,689 \\
\hline
\end{tabular}

Pembuatan Simulasi Program.

Proses pembuatan simulasi program dengan ketebalan isolasi mineral wool $=50$ $\mathrm{mm}$ berdasarkan data parameter diatas adalah sebagai berikut

1. Menghitung jumlah panas yang hilang secara konveksi pada saluran pipa tanpa menggunakan bahan isolasi :

$$
Q=\bar{h} A \Delta T
$$

Konduktivitas termal konveksi rata-rata dari permukaan pipa ke lingkungan $(\bar{h})$, dicari dengan menggunakan rumusrumus bilangan bilangan Nusselt, Grashof, Reyleigh dan Prandtl,:

a) Menentukan nilai Tf (suhu rata-rata) yang didapatkan dari rata-rata suhu operasional dan suhu lingkungan. $\mathrm{Tf}=(423,15+308,15) / 2=365,65^{\circ} \mathrm{K}$

b) Berdasarkan nilai $\mathrm{Tf}$ diatas maka didapatkan nilai $ß$ (koefisien jumlah ekspansi)

$B=1 / T f=1 / 365,65=0.002734856$

c) Berdasarkan nilai $\mathrm{Tf}$ diatas maka didapatkan nilai $\mathrm{k}, \operatorname{Pr}$ dan $\mathrm{v}$ dengan cara melihat tabel 3.

$$
\begin{aligned}
& \mathrm{k}=0,031163 \mathrm{~W} / \mathrm{m} \cdot \mathrm{k} \\
& \mathrm{Pr}=0,694496 \\
& \mathrm{v}=0,0000224 \mathrm{~m}^{2} / \mathrm{s}
\end{aligned}
$$

d) Dari nilai - nilai diatas maka dapat dihitung nilai $\mathrm{Ra}, \mathrm{Nu}$ dan $\bar{h}$ sebagai berikut :

$$
\begin{aligned}
& R a=\frac{g \beta\left(T_{1}-T_{2}\right) L^{3}}{V^{2}} \cdot \operatorname{Pr} \\
& =\frac{9.8 \times 0,002734856(423,15-308,15) 0,1683^{3}}{0,0000224^{2}} \cdot 0,694496 \\
& \quad=20.393 .618,25
\end{aligned}
$$

$$
\begin{aligned}
\overline{N u} & =\left\{0,60+\frac{0,387 R a^{1 / 6}}{\left[1+(0.559 / P r)^{9 / 16}\right]^{8 / 27}}\right\}^{2} \\
& =\left\{0,60+\frac{0,387 \times 20.393 .618,25^{\frac{1}{6}}}{\left[1+\left(\frac{0.559}{0,694496}\right)^{\frac{9}{16}}\right]^{\frac{8}{27}}}\right\}^{2} \\
& =33,62 \\
\bar{h} & =\frac{N u \cdot k}{L} \\
& =\frac{33,62 \times 0,031163}{0,1683} \\
& =6,23 \mathrm{~W} /\left(\mathrm{m} .{ }^{\circ} \mathrm{K}\right)^{2}
\end{aligned}
$$

Sehingga analisa nilai jumlah kehilangan panas secara konveksi adalah

$$
\begin{aligned}
Q & =\bar{h} A \Delta T \\
& =6,23 \times 26,423 \times(423,15-308,15) \\
& =18.819 \mathrm{~W}
\end{aligned}
$$


2. Menghitung jumlah panas yang hilang apabila menggunakan bahan isolasi berupa mineral wool, calsium silicate dan ceramic fiber blanket. berikut tahapan proses perhitungan kerugian panas dengan menggunakan mineral wool ketebalan isolasi $50 \mathrm{~mm}$ :

a) Resistansi termal konduksi di dalam isolasi dengan ketebalan isolasi 50 $\mathrm{mm}$ adalah :

$$
\begin{aligned}
& \mathrm{R} \text { (isolasi) }=\frac{\operatorname{In} \frac{\mathrm{R} 3}{\mathrm{R} 2}}{2 \pi \mathrm{k}_{\text {iso }} \mathrm{L}_{\text {pipa }}} \\
& =\frac{\operatorname{In} 1,594}{2 \times 3,14 \times 0,049 \times 50} \\
& =\frac{0,46624}{15,386} \\
& =0,03030^{\circ} \mathrm{K} / \mathrm{W}
\end{aligned}
$$

b) Resistansi termal konduksi di dalam aluminium dengan ketebalan aluminium $0,5 \mathrm{~mm}$ adalah :

$$
\begin{aligned}
& R(\text { aluminium })=\frac{\operatorname{In} \frac{\mathrm{R} 4}{\mathrm{R} 3}}{2 \pi \mathrm{k}_{\text {alm }} \mathrm{L}_{\text {pipa }}} \\
& =\frac{\operatorname{In} 1,037}{2 \times 3,14 \times 237 \times 50} \\
& =\frac{0,03633}{74.418} \\
& =0,000000488188^{\circ} \mathrm{K} / \mathrm{W}
\end{aligned}
$$

c) Resistansi termal konveksi dari permukaan aluminium ke udara adalah :

$$
\mathrm{R}(\text { konveksi })=\frac{1}{\mathrm{~h} .\left(2 \pi \mathrm{R} 4 \mathrm{~L}_{\mathrm{pipa}}\right)}
$$

Konduktivitas termal konveksi rata-rata dicari dengan menggunakan rumus bilangan bilangan Nusselt, Grashof, Reyleigh dan Prandtl. diperoleh nilai $\bar{h}: 10,48 \mathrm{~W} /\left(\mathrm{m} .{ }^{\circ} \mathrm{K}\right)^{2}$, Sehingga analisa nilai jumlah panas yang hilang secara konveksi adalah

$$
\begin{aligned}
& \mathrm{R}(\text { konveksi })=\frac{1}{\mathrm{~h} .\left(2 \pi \mathrm{R} 4 \mathrm{~L}_{\text {pipa }}\right)} \\
& =\frac{1}{10,48(2 \times 3,14 \times 0,11415 \times 50)} \\
& =0,00266215^{\circ} \mathrm{K} / \mathrm{W}
\end{aligned}
$$

Sehingga jumlah resistansi termalnya adalah $\sum \mathrm{R}=\mathrm{R} 1+\mathrm{R} 2+\mathrm{R} 3$, maka nilai $\mathrm{Q}$ dapat dihitung :

$$
\begin{aligned}
& Q=\frac{\left(T_{a}-T_{u}\right)}{\sum R} \\
& =\frac{(423,15-308,15)}{0,03030+0,000000488188+0,00266215} \\
& =3.489 \text { Watt }
\end{aligned}
$$

Untuk analisa kehilangan panas ketebalan isolasi $25 \mathrm{~mm}$ dan $75 \mathrm{~mm}$ dapat dihitung dengan cara yang sama.

Berdasarkan langkah-langkah diatas maka dapat dibuat program simulasi kerugian panas dengan menggunakan software Microsoft Excell, berikut ini adalah tampilan programnya sesuai gambar 2 .

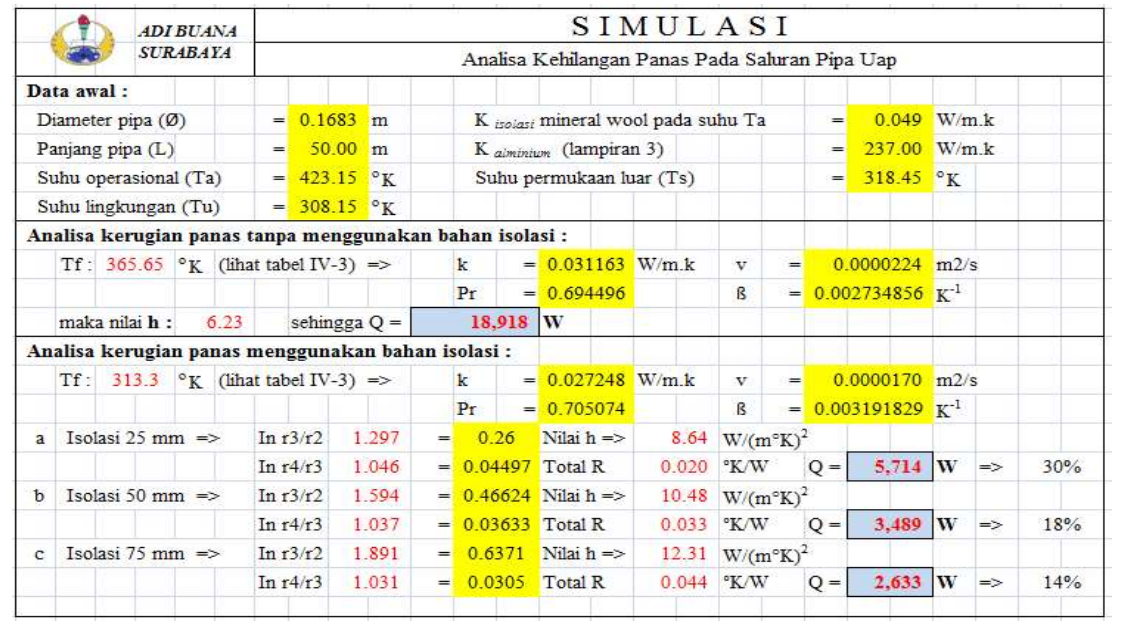

Gambar 2. Tampilan program simulasi kehilangan panas 


\section{Beberapa Hasil Simulasi.}

Ringkasan hasil simulasi dari penelitian yang sudah dilakukan dijabarkan dalam tabel 4 dan digambarkan dengan grafik hubungan antara ketebalan isolasi terhadap heat loss sesuai gambar 3 .

Tabel 4. Ringkasan hasil simulasi analisa kerugian panas pada diameter pipa saluran 168,3 $\mathrm{mm}\left(6\right.$ inch) beberapa jenis bahan isolasi dengan suhu operasional $150^{\circ} \mathrm{C}$

\begin{tabular}{|c|c|c|c|c|c|}
\hline \multirow[b]{2}{*}{ No } & \multirow[b]{2}{*}{ Jenis bahan } & \multirow{2}{*}{\multicolumn{2}{|c|}{ Jenis simulasi dengan ketebalan }} & \multicolumn{2}{|c|}{ Hasil simulasi } \\
\hline & & & & Nilai (watt) & $\%$ \\
\hline \multirow{4}{*}{1.} & \multirow{4}{*}{ Mineral wool } & \multicolumn{2}{|c|}{ Heat loss tanpa bahan isolasi } & 18.918 & 100 \\
\hline & & \multirow{3}{*}{$\begin{array}{l}\text { Heat loss dengan bahan } \\
\text { isolasi }\end{array}$} & $25 \mathrm{~mm}$ & 5.714 & 30 \\
\hline & & & $50 \mathrm{~mm}$ & 3.489 & 18 \\
\hline & & & $75 \mathrm{~mm}$ & 2.633 & 14 \\
\hline \multirow{4}{*}{2.} & \multirow{4}{*}{$\begin{array}{l}\text { Calcium } \\
\text { silicate }\end{array}$} & \multicolumn{2}{|c|}{ Heat loss tanpa bahan isolasi } & 18.918 & 100 \\
\hline & & \multirow{3}{*}{$\begin{array}{l}\text { Heat loss dengan bahan } \\
\text { isolasi }\end{array}$} & $25 \mathrm{~mm}$ & 7.774 & 41 \\
\hline & & & $50 \mathrm{~mm}$ & 4.913 & 26 \\
\hline & & & $75 \mathrm{~mm}$ & 3.756 & 20 \\
\hline \multirow{4}{*}{3.} & \multirow{4}{*}{$\begin{array}{c}\text { Ceramic fiber } \\
\text { blanket }\end{array}$} & \multicolumn{2}{|c|}{ Heat loss tanpa bahan isolasi } & 18.918 & 100 \\
\hline & & \multirow{3}{*}{$\begin{array}{l}\text { Heat loss dengan bahan } \\
\text { isolasi }\end{array}$} & $25 \mathrm{~mm}$ & 6.756 & 36 \\
\hline & & & $50 \mathrm{~mm}$ & 4.197 & 22 \\
\hline & & & $75 \mathrm{~mm}$ & 3.188 & 17 \\
\hline
\end{tabular}

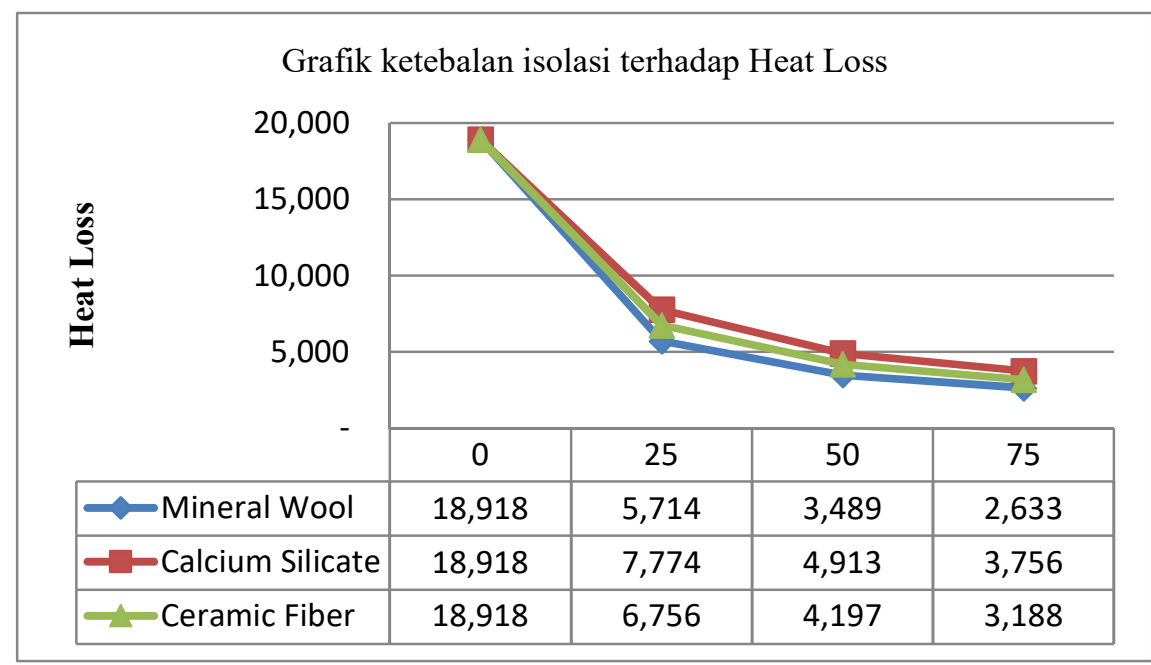

Gambar 3. Grafik ketebalan isolasi terhadap nilai heat loss 


\section{PEMBAHASAN.}

Pada analisa dengan suhu operasional $150{ }^{\circ} \mathrm{C}$ pada tabel 4 dan gambar 3 , kerugian panas dengan menggunakan bahan isolasi tebal $25 \mathrm{~mm}$ yang memiliki nilai terkecil adalah isolasi mineral wool dengan hasil 5.714 watt $(30 \%)$, lalu ceramic fiber blanket dengan hasil 6.756 watt $(36 \%)$ dan calcium silicate dengan hasil 7.774 watt $(41 \%)$. Analisa kerugian panas menggunakan bahan isolasi tebal $50 \mathrm{~mm}$ yang memiliki nilai terkecil adalah isolasi mineral wool dengan hasil 3.489 watt $(18 \%)$, lalu ceramic fiber blanket dengan hasil 4.197 watt $(22 \%)$ dan calcium silicate dengan hasil 4.913 watt (26\%). Sedangkan analisa kerugian panas menggunakan bahan isolasi tebal $75 \mathrm{~mm}$ yang memiliki nilai terkecil adalah isolasi mineral wool dengan hasil 2.633 watt (14\%), lalu ceramic fiber blanket dengan hasil 3.188 watt $(17 \%)$ dan calcium silicate dengan hasil 3.756 watt (20\%).

Ketiga bahan isolasi tersebut mampu meminimalisasi kehilangan panas (heat loss) dengan hasil yang bervariasi, namun hasil yang terbaik adalah pada bahan isolasi mineral wool yang secara data spesifikasi memiliki termal konduktivitas yang kecil dibandingkan lainya.

\section{KESIMPULAN DAN SARAN}

Berdasarkan penelitian yang sudah dilakukan mengenai analisa pemilihan bahan isolasi yang tepat untuk meminimalisasikan kehilangan panas menunjukkan bahwa nilai heat loss yang dihasilkan dari ketiga bahan isolasi berbeda-beda. Nilai perbedaan tersebut sangat dipengaruhi oleh sifat karakteristik bahan dan termal konduktivitas bahan isolasi tersebut. Nilai yang dihasilkan menggambarkan pentingnya bahan tersbut digunakan sebagai pelindung saluran pipa uap panas dan sangat mempengaruhi seberapa besar uap yang dapat diselamatkan untuk produksi. Penggunaan bahan aluminium tidak terlalu mempengaruhi hasil nilai kehilangan panas, namun sangat direkomendasikan agar menjaga ketahanan bahan isolasi yang dipasang. Dari nilai - nilai kehilangan panas yang diperoleh tersebut diharapkan perusahaan dapat memilih diantara ketiga bahan tersebut yang paling tepat digunakan dalam industrinya. Penelitian ini hanya menganalisa tiga jenis bahan isolasi dari sisi nilai kehilangan panas (heat loss), sedangkan sangat banyak sekali jenis bahan isolasi yang ada dipasaran dan juga selanjutnya agar bisa dihitung analisa biaya yang ditimbulkan dari kehilangan panas tersebut untuk mendapatkan penghematan yang maksimal baik dari sisi bahan bakar, jam operasional dan pemeliharaan umur mesin.

\section{DAFTAR PUSTAKA}

Anonymous, Insulation and Refractories, Bureau of Energy Efficiency http://www.enercon.gov.pk/ images/ pdf/2ch5.pdf (tanggal mengunduh : 7 Desember 2013)

Distantina Sperisa, Critical Insulation Thicknes, http://distantina.staff.uns. ac.id/files/2009/09/critical-insulation-thickness1.pdf (tanggal mengunduh : 23 Desember 2013)

Donald R.Pitts and Leighton E.Sissom, 2008. Perpindahan Kalor, edisi 2, Erlangga, Jakarta.

Frank Kreith, 1997. Prinsip Perpindahan Panas, edisi 3, Erlangga, Jakarta.

J.P. Holman, 1995. Perpindahan Kalor, edisi 6, Erlangga, Jakarta.

Jokosetyadjo, M.J, 2006. Ketel Uap, cetakan ke 4, Pradnya Paramita, Jakarta.

Raswari, 2010. Teknologi dan Perencanaan Sistem Perpipaan, Universitas Indonesia, Jakarta

Santoso,Gempur, 2012. Metodologi Penelitian Kuantitatif dan Kualitatif. Prestasi Pustaka Publisher. Jakarta 